\title{
TRANSFORMACIONES EN LA INDUSTRIA SIDERÚRGICA DURANTE LA POST-CONVERTIBILIDAD
}

\author{
Juan E. Santarcángelo* \\ Julia Strada**
}

enviado: octubre 2013 - aceptado: marzo 2014

\begin{abstract}
Resumen
La devaluación de la moneda y los cambios en los precios relativos, brindaron un contexto propicio para que la industria manufacturera, y en particular el sector siderúrgico, crecieran a tasas superiores al promedio durante la postconvertibilidad. En este contexto, el propósito del trabajo es analizar las rupturas y continuidades que exhibe el sector siderúrgico entre los períodos de convertibilidad y postconvertibilidad, para lo cual se estudiarán las características del proceso productivo, el papel del complejo en el crecimiento industrial, la vinculación de la siderurgia con el sector externo, así como la evolución de la productividad, ocupación, salario y rentabilidad del sector. Por último se abordarán los principales desafíos que enfrenta el sector de cara a consolidar el actual proceso de desarrollo.
\end{abstract}

Clasificación JEL: L61, O54, L16

Palabras clave: siderurgia, postconvertibilidad, Argentina, empleo.

\begin{abstract}
The devaluation of the currency and the changes in relative prices provided a good environment for the manufacturing industry, especially the steel industry, to grow at above-average rates during the postconvertibility regime. In this con-

* Phd in Economics. Investigador del CONICET y docente de la Universidad Nacional de General Sarmiento y FLACSO- UBA. Juan M. Gutierrez 1150, Los Polvorines, Pcia de Bs As - Dirección electrónica: jsantar@gmail.com.

** Lic. en Ciencia Política de la Universidad Nacional de Rosario y Maestranda en Economía Política en la Facultad Latinoamericana de Ciencias Sociales, Buenos Aires
\end{abstract}


text, the aim of the paper is to analyze the ruptures and continuities that the steel sector exhibits between the convertibility and postconvertibility regimes focusing on the main characteristics of the production process, the role of the sector in manufacturing growth, the relation with external markets and the steel's evolution of productivity, employment, wages and profitability. Finally we will address the main challenges facing the sector in order to consolidate the current development process.

JEL Classification: L61, O54, L16

Keyword: iron, steel, postconvertibility regime, Argentina, employment.

\section{INTRODUCCIÓN}

La industria siderúrgica ha sido, en la historia económica argentina, un sector clave para el desarrollo nacional y su centralidad radica en que es una rama que influye en una gama amplia de actividades tales como la producción automotriz, bienes de capital, infraestructura, construcción, electrodomésticos y bienes de consumo durables, entre otros (Moya, 2012; Cohn, 2009). En el caso argentino, las transformaciones experimentadas por dicho sector se han sucedido al compás de los procesos de industrialización que tuvieron lugar durante la primer y segunda industrialización por sustitución de importaciones (ISI), y a las dinámicas de desindustrialización instaurados con el modelo de acumulación basado en la valorización financiera y que estuvo vigente entre 1976 y el año 2001.

Si bien las políticas de apertura económica y desindustrialización tuvieron severos impactos en la industria manufacturera local, la industria siderúrgica logró consolidar cierto patrón de crecimiento durante el modelo de valorización financiera, que no estuvo exento de transformaciones y que se sustentó fundamentalmente en ciertas políticas de promoción sectorial y en la obtención de beneficios extraordinarios por parte de ciertas empresas vinculadas al poder político de turno (Azpiazu et. al., 2007; Jabbaz, 1996). En este contexto, los años noventa vieron como el sector lograba importantes mejoras en los niveles de productividad sustentados en una constante reducción del empleo y como crecientemente la producción local era destinada a mercados extranjeros con el objeto de sortear los efectos de una demanda interna que se veía reducida constantemente.

La crisis del año 2001, la devaluación del año siguiente y la consecuente alteración de los precios relativos de la economía, brindaron un contexto propi- 
cio para que la industria manufacturera, por primera vez desde el abandono del modelo de industrialización por sustitución de importaciones, creciera a tasas superiores al agregado de la economía (Azpiazu et. al, 2007, Santarcángelo et. al, 2011 y 2012). En este marco, uno de los sectores que claramente ha mostrado un desempeño distintivo en relación a lo acontecido durante los años noventa, es el sector siderúrgico que se inserta como una de las principales ramas "ganadoras" de la postconvertibilidad (Santarcángelo et. al, 2012; Basualdo et. al, 2012; Schorr et. al, 2007).

En este contexto, el propósito del presente trabajo es analizar las rupturas y continuidades que exhibe el sector siderúrgico entre los períodos de convertibilidad y postconvertibilidad para lo cual se analizarán las principales características del proceso productivo, el papel del complejo en el crecimiento del sector industrial, la vinculación de la siderurgia con el sector externo, así como la evolución de la producción, productividad, ocupación, salario y rentabilidad del sector.

De acuerdo a estos objetivos, el trabajo se estructura en tres secciones luego de esta breve introducción. En la siguiente sección se propone revisar las características centrales del sector durante los años noventa y el impacto que ha tenido la profundización de las reformas neoliberales en Argentina sobre el complejo. Una vez en claro esta dinámica, en la segunda sección se propone examinar cómo ha evolucionado la rama siderúrgica en los últimos años enfatizando en las continuidades y rupturas que presenta el actual desempeño en relación a lo registrado durante la década del noventa en materia productiva y de generación de empleo. Por último, cerramos el trabajo presentando las principales conclusiones del mismo y dando cuenta de los desafíos centrales que enfrenta el sector de cara a consolidar el actual proceso de desarrollo.

\section{LA SIDERURGIA DURANTE EL RÉGIMEN DE CONVERTIBILIDAD}

La crisis hiperinflacionaria de 1989 da por tierra con el primer gobierno constitucional electo luego del fin de la última dictadura. Pero, fundamentalmente permite terminar de remover las restricciones estructurales que impedían el desarrollo y consolidación del patrón de valorización financiera (Basualdo, 2011). En esta dirección, las medidas implementadas desde inicios de la década de los noventa buscaron redefinir el carácter del Estado y profundizar las políticas aplicadas por la dictadura que tenían como fin modificar aún más la distribución del ingreso. Entre las medidas más relevantes en este sentido se encuentran la sanción de la Ley de Emergencia Económica, la Ley de Reforma del Estado (que regula la privatización 
empresas públicas), la implementación del régimen de convertibilidad así como otras medidas de reforma impositiva, de flexibilización laboral y de liberalización de los flujos de capitales. Como resultado de estas políticas se produjo una profundización del proceso de desindustrialización. De esta manera, los récords negativos que registraba el sector industrial en materia productiva y de generación de empleo comenzaron a superarse casi de modo constante (Basualdo, 2006).

En relación a la evolución del sector siderúrgico en particular, la década de los noventa presenta un conjunto de transformaciones que serían decisivas a la hora de estudiar la evolución del sector (Azpiazu, et. al, 2007). La primera de ellas se corresponde con la privatización de las empresas estatales que derivó en una oligopolización del sector que se profundiza a lo largo de toda la década ${ }^{1}$. Cabe destacar que este proceso de oligopolización de la siderurgia también ocurre a nivel mundial y responde a las propias características del sector resultantes de sus altas barreras de entrada que exigen cantidades masivas de capital y escalas muy elevadas. Sin dudas la industria siderúrgica se considera "pesada" porque supone inversión elevada de capital por unidad de producto, y esta característica se acentúa durante las últimas décadas del siglo XX (Schvarzer et. al, 2005).

El otro fenómeno que en paralelo a la privatización de empresas públicas tuvo un rol central para reconfigurar el modelo productivo del sector a comienzos de los años noventa, residió en la aplicación de las tradicionales políticas económicas de corte neoliberal de reducción de gastos y participación del Estado en la vida económica que afectaron a la industria manufacturera en general y al sector siderúrgico en particular. Fundamentalmente pueden destacarse dos medidas que tuvieron un impacto significativo sobre el complejo bajo análisis. La primera de estas medidas corresponde a la apertura de la economía, que si bien tuvo como efecto principal el abaratamiento del precio de la maquinaria y los insumos impor-

1 La privatización del complejo estatal también ha derivado en procesos de concentración a través de transferencias y fusiones así como segmentación del mercado. El Grupo Techint, comprador de SOMISA, decide abandonar la producción de palanquilla y laminados no planos como rieles y estructuras, lo cual determina una especialización en productos planos. En paralelo, se avanzó en la segmentación del mercado: Acindar se especializa en los productos no planos como alambrón y hierro redondo. Posteriormente en 1993 se fusionan en Siderar (Grupo Techint), la ex SOMISA, Propulsora Siderúrgica, Bernal, Sidercolor y Sidercrom. Por parte de Acindar, ésta adquiere Aceros Bragados, La Cantábrica, Fortunato Bonelli, Previlám, Navarro, Establecimiento Siderúrgico San José y Rauna. Asimismo, la concentración se profundiza con una nueva ola de adquisiciones que se produce entrados los años 90, cuando Acindar compra una 8 empresas entre 1997 y 1998 (Sampa, Indema, Puar, Clamet, Tejimet, M. Heredia y Cía., Impeco y Laminfer) y Armax en el año 2001. Por su parte, Techint adquiere Comesi en 1997 (Azpiazu et. al., 2007). 
tados; el desarrollo de diversas actividades de lobby y de aplicación de medidas anti-dumping implicó que la apertura no afectara a todos los actores de manera similar y que salieran claramente favorecidas las empresas que controlaban el mercado. La segunda medida central que reconfiguró el sector fue la desregulación económica, la cual conllevó a la derogación de la ley de reserva de cargas, liberalización de precios y disolución de instituciones regulatorias de la actividad siderúrgica (Azpiazu et. al, 2007, p. 52).

I.1 Producción, exportaciones e importaciones del sector siderúrgico durante la convertibilidad

En términos productivos se pueden identificar tres etapas dentro del régimen de convertibilidad y que se corresponden con los subperíodos 1991-1993, 1994-1997 y 1998-2001 (Azpiazu et. al, 2007). La información general sobre las principales características de oferta y demanda de estas etapas se presenta a continuación en el cuadro 1.

Cuadro 1 Oferta y demanda de productos siderúrgicos. En miles de toneladas y promedio anual para cada período.

\begin{tabular}{lcccc}
\hline & Ochentas & Convertibilidad & & \\
\hline & $1980-1989$ & $1990-1993$ & $1994-1997$ & $1998-2001$ \\
\hline Producción & & & & \\
Laminados Terminados & 2.890 & 2.801 & 3.847 & 3.986 \\
No planos & 1.168 & 938 & 1.214 & 1.159 \\
Planos & 1.368 & 1.275 & 1.891 & 2.169 \\
Tubos sin costura & 354 & 588 & 742 & 658 \\
\hline & & & & \\
Exportaciones (I) & 855 & 1.225 & 1.296 & 1.769 \\
Laminados Terminados & 299 & 210 & 256 & 246 \\
No planos & 357 & 535 & 530 & 1.014 \\
Planos & 199 & 480 & 510 & 509 \\
Tubos sin costura & & & & \\
\hline
\end{tabular}


Importaciones (II)

Laminados Terminados

259

517

752

989

No planos

45

82

265

347

Planos

201

426

457

607

Tubos sin costura

13

9

30

35

Saldo comercial $($ III) $=$

(I)-(II)

$\begin{array}{lcccc}\text { Laminados Terminados } & 596 & 708 & 544 & 780 \\ \text { No planos } & 254 & 128 & -9 & -101 \\ \text { Planos } & 156 & 109 & 73 & 407 \\ \text { Tubos sin costura } & 186 & 471 & 480 & 474\end{array}$

Consumo Aparente

Laminados Terminados

2.295

2.093

3.303

3.206

No planos

915

809

1.223

1.260

Planos

1.213

1.167

1.818

1.762

Tubos sin costura

167

117

262

184

Fuente: Elaboración propia en base a Azpiazu (2007) y a la base de datos Centro de Industriales Siderúrgicos (CIS).

Como se puede apreciar, la primera fase se corresponde con la reestructuración sectorial de comienzos de la década (1990-1993), que comienza con la paridad cambiaria y apertura de la economía y fundamentalmente se corresponde con la privatización de Altos Hornos Zapla en julio de 1992 y del complejo estatal SOMISA en noviembre de 1992 (von Storch, 2005; Cohn, 2009). El proceso de privatización y reforma del sector provocó una modificación radical en términos productivos y sectoriales (Jabbaz, 1996), ya que no sólo favoreció la profundización de la concentración del mercado siderúrgico en donde Techint y Acindar pasaron a ejercer un dominio excluyente; sino que tuvo impactos productivos dado que Aceros Paraná (ex SOMISA) abandonó la producción de productos no planos e inició un proceso de integración vertical con Propulsora Siderúrgica S.A (Azpia- 
zu et. al, 2007, p. 47).

En estos años, y de acuerdo a la información aportada por el Cuadro 1, la producción total de Laminados Terminados se mantuvo igual a la década del ochenta y, en consonancia con las modificaciones del complejo estatal, marcó una caída del orden del 20\% en la producción de laminados no planos. No obstante, se evidencia un crecimiento en la producción y de la exportación de tubos sin costura (se incrementaron las exportaciones en este rubro en un 141\%), al igual que las exportaciones de laminados planos se incrementaron aunque en menor medida (en un 50\% aproximadamente). Como resultado, si bien el subperíodo se encontró atravesado por reestructuraciones productivas, la incipiente dinámica exportadora que algunos rubros comenzaron a ostentar permitió obtener un saldo comercial positivo y superior en un 18\% al obtenido en el periodo 1980-1989.

La segunda fase de los años noventa se corresponde con la "etapa de oro" de la convertibilidad y abarca el subperíodo 1994-1997, en el cual se produce un crecimiento del sector en función del aumento de la demanda interna de productos siderúrgicos, al calor del crecimiento económico general de la economía. En efecto, como refleja el Cuadro 1 la producción del sector creció en promedio casi un $40 \%$ más con respecto a la primera fase de la convertibilidad en un contexto donde el consumo doméstico aumentó casi un 60\% mientras que las exportaciones crecieron sólo un 5\% y las importaciones un 45,5\%. Este aumento en los volúmenes de producción se produce como consecuencia de una remodelación de las instalaciones en la ex $\mathrm{SOMISA}^{2}$, que permite de manera conjunta con la modernización en Acindar y Siderca, el aumento de la capacidad instalada en la industria siderúrgica local (Schvarzer et. al, 2005). En relación a la variación por tipo de productos siderúrgicos, se encuentra un incremento en la producción de todas las categorías: laminados no planos (en un 30\%), laminados planos (en un $48 \%$ ) y tubos sin costura (en un 26\%). Asimismo, laminados no planos y tubos sin costura mejoran levemente su desempeño exportador, mientras que laminados planos sufre una modesta caída. Finalmente, y producto de la menor dinámica exportadora y del incremento de las importaciones en un 45\% (particularmente de laminados no planos y tubos sin costura), el saldo comercial resultante se mantiene positivo pero muestra una caída del orden del 23\% respecto al subperíodo 1990 1993. Esta disminución en la dinámica exportadora (sólo creció un 5\%) y la caída en el saldo comercial sectorial se explica sustancialmente por la recuperación del consumo interno.

2 Al convertirse en Siderar (Grupo Techint), absorbe otras actividades de la rama, como es el caso de Propulsora Siderúrgica, que elaboraba laminados en frío. 
Por último, la tercera fase se caracteriza por el inicio de la larga recesión que finaliza con la crisis de la convertibilidad (1998-2001), la cual provoca la desaceleración del crecimiento del sector debido a la contracción de la demanda interna. Si bien la crisis de la economía argentina fue la peor de su historia, la rama siderúrgica no tuvo un mal desempeño agregado a pesar de la mencionada desaceleración del ritmo de crecimiento de la economía en su conjunto.

En virtud de los datos del Cuadro 1, se evidencia un menor crecimiento de la producción de laminados terminados (solo del 3\%) respecto a la fase previa. Cae la producción de laminados no planos y de tubos sin costura, mientras que laminados planos muestra un incremento del 14\%. Estos últimos muestran, a su vez, una fuerte dinámica exportadora, que aumenta prácticamente en un $100 \%$ respecto a la fase previa, mientras que los niveles de exportación de laminados no planos y tubos sin costura se mantienen iguales. En suma, a pesar del incremento importador (de un 31\%), el saldo comercial sectorial aumenta en un $43 \%$. En el marco de una contracción sensible de la producción económica del país y de una caída del consumo interno del sector de casi un 3\% en el tercer subperíodo 1998-2001 respecto a la fase expansiva previa, uno de los aspectos novedosos de esta etapa es que las empresas logran colocar sus productos en los mercados externos (Jerez, 2008). Esto explica el aumento sensible en los niveles de exportación del sector, los cuales se incrementan más de un $36 \%$ en relación a la etapa previa, y responden fundamentalmente al aumento de los volúmenes exportados de los laminados planos. Durante esta etapa el sector consolida una nueva inserción internacional como proveedor de este tipo de bienes ${ }^{3}$.

Otro modo de dar cuenta de este fenómeno, y que se presenta en el gráfico 1, es a partir de la observación a lo largo de todo el periodo de la convertibilidad de la evolución del peso de las exportaciones sobre el valor bruto de producción y del peso de las importaciones sobre el consumo aparente. Como se puede apreciar en el gráfico, a lo largo de la convertibilidad la importancia de las exportaciones

3 Jerez, P. (2008) en su trabajo "La exportación como destino alternativo para la producción siderúrgica argentina entre 1976 y 1990", remarca la orientación exportadora que a partir de dicho periodo (1976-1990) adquiere la siderurgia en función de las transformaciones acaecidas en la economía argentina: el abandono el modelo de industrialización por sustitución de importaciones y la implantación de la valorización financiera, que provocaron una reducción de la incidencia del mercado interno. A este cambio estructural se suman los factores sectoriales, que alimentaron la orientación exportadora de la siderurgia. Entre ellos pueden destacarse la situación de la industria siderúrgica mundial, la incorporación de nueva tecnología, los privilegios otorgados a través de las leyes de promoción, y la concentración productiva en una menor cantidad de empresas. 
de productos siderúrgicos en relación al volumen de producción sectorial se ha incrementado sensiblemente. En este sentido, el gráfico refleja que el peso de las exportaciones en relación al volumen bruto de producción prácticamente se duplicó desde comienzos de los años noventa hasta el año 2001, terminando con valores significativos que dan cuenta que casi el 32\% de la producción realizada se vendió en mercados externos. En otras palabras, las empresas que operan en el sector lograron durante estos años, vía el aumento en su volumen de exportaciones, sortear las limitaciones que imponía un mercado interno en crisis y que no parecía mostrar signos de recuperación. El destino de las exportaciones fue centralmente a Estados Unidos (20\%), Brasil (9\%) y Paraguay (7\%). Por otra parte, el cociente de importaciones sobre consumo aparente que refleja el peso que tienen las importaciones en relación al nivel de consumo local, creció a una tasa menor que el cociente antes mencionado y terminó en el año 2001 con un crecimiento del $35 \%$ en relación a los valores que registraba en el año 1993. El origen de la misma muestra un nivel de concentración mucho mayor que con lo que sucede con las exportaciones, siendo Brasil el principal origen (58\%), seguido por China $(5 \%)$ y en menor medida por Estados Unidos (4\%).

Gráfico 1. Evolución de las exportaciones sobre el volumen bruto de producción y de las importaciones sobre el consumo aparente, 1993-2001.

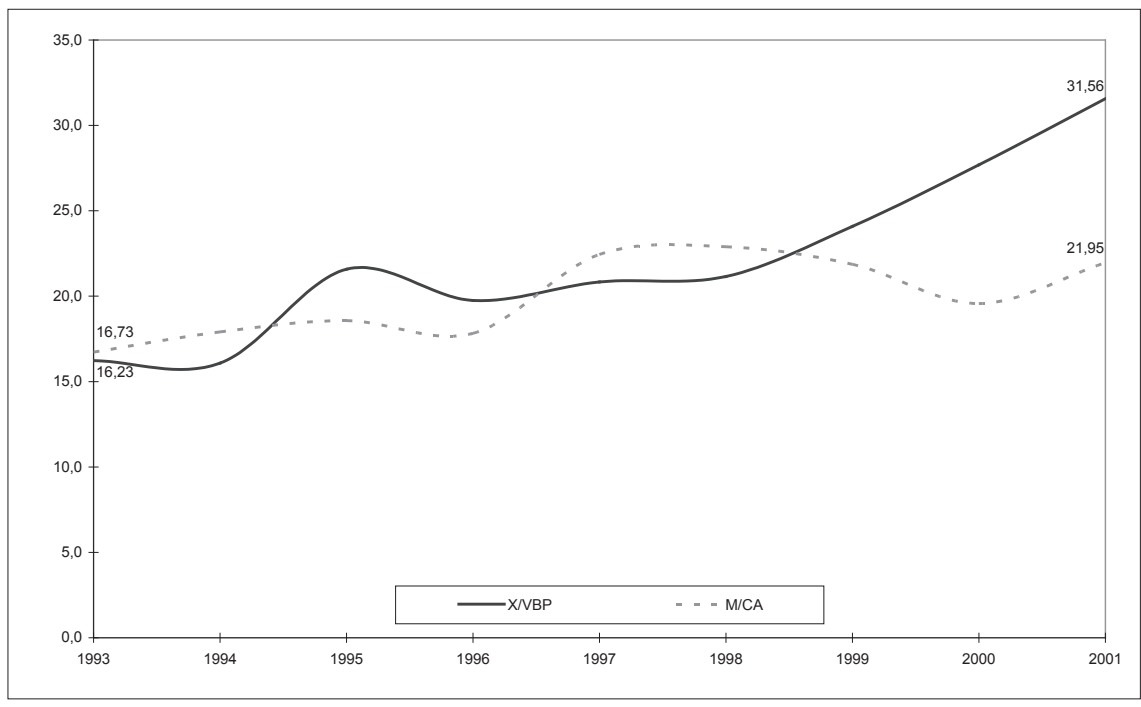

Fuente: Elaboración propia en base a CEP (2012) 
I.2 Dinámica de empleo, productividad laboral y salarios

Una vez desarrollada la dinámica productiva del sector y su vinculación con el sector externo, resulta significativo analizar la evolución que ha mostrado la productividad laboral, la generación de empleo sectorial y la evolución de los salarios. Para analizar los dos primeros fenómenos se presentan en el gráfico 2 la evolución de la producción, la productividad laboral por obrero ocupado y la evolución del empleo que tuvo el sector durante los años 90s.

Como se puede apreciar en el gráfico 2, la evolución de la productividad por obrero ocupado exhibe una tendencia creciente para las dos primeras etapas de la convertibilidad, en tanto que la tasa de crecimiento promedio de la fase 19941997 es un $25 \%$ inferior a la registrada durante la fase 1991-1993. A su vez, en la etapa recesiva de vigencia del régimen convertible (1998-2001), la productividad por obrero ocupado se estanca en un contexto en el que la producción muestra una tendencia decreciente producto de la crisis de finales de la convertibilidad (del orden del 17\%). En síntesis, tomando en conjunto la década de los noventa, la productividad laboral crece enormemente y casi duplica el valor que tenía al comienzo del régimen convertible.

Gráfico 2. Evolución de la producción en la industria siderúrgica, de la cantidad de ocupados y de la productividad por ocupado, 1991-2001 (1993=100)

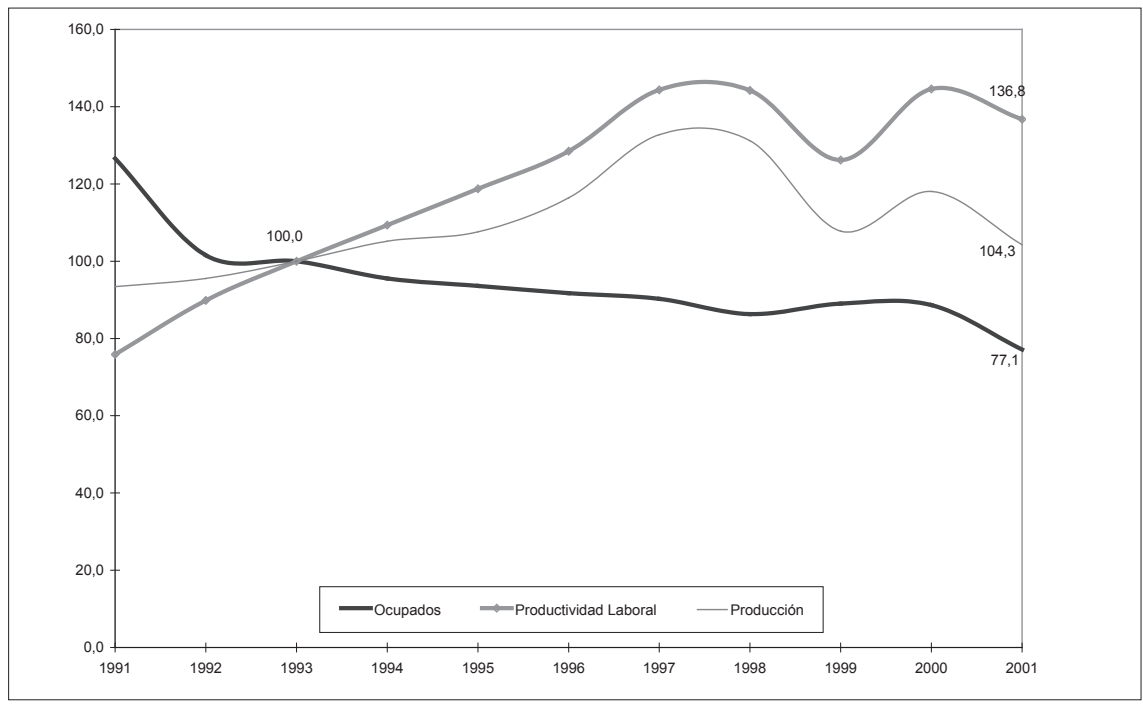


Fuente: Elaboración propia a partir de Azpiazu et. al. (2007) y Alacero (2012)

Esta dinámica registrada en la productividad se explica en buena medida por la clara tendencia de pérdida de gravitación del factor trabajo en el sector siderúrgico, expresada en el constante descenso del nivel de ocupación sectorial a lo largo de la década. Mientras la siderurgia inicia su fase de crecimiento denominada "edad de oro", el nivel de desempleo de la economía argentina supera por primera vez en su historia los dos dígitos. Esto se corresponde con el propio comportamiento de las variables ocupacionales a nivel sectorial, dado que la cantidad de ocupados del sector exhibe una clara tendencia decreciente con dos fases extremadamente agudas y que coinciden con el comienzo y el final de la convertibilidad.

En esta dirección, si bien en 1989 la cantidad de ocupados del sector era de 32.148 personas, solo cuatro años más tarde hacia el final de la primera fase de la convertibilidad, el número de ocupados desciende a 17.084 personas. Esta gran reducción de puestos de trabajo en la industria siderúrgica no sólo es producto de la profundización de las políticas neoliberales aplicadas durante el gobierno de Alfonsín; sino que también es el resultado específico de la privatización de SOMISA que provocó una considerable reducción del personal ocupado en el sector que significaron aproximadamente 6 mil puestos de trabajo entre retiros voluntarios y despidos (von Storch, 2005). Por otra parte, al final de la convertibilidad y en un contexto donde los niveles generales de desempleo y subempleo de la economía rondaban el $25 \%$, el nivel de empleo sectorial se estabiliza, para contraerse nuevamente durante los últimos dos años y terminar la década con una cantidad de ocupados en el sector de tan sólo 13 mil trabajadores.

Lo interesante y paradójico de este fenómeno es que el proceso de expulsión de mano de obra se da en un contexto de fuerte aumento de la productividad que al crecer a tasas mayores que las registradas por los salarios reales, tuvo importantes consecuencias en términos de distribución del ingreso. Para apreciar este fenómeno, en el gráfico 3 estudiamos la evolución de los salarios, la productividad laboral y la relación entre salarios y la productividad laboral que es una proxy de cómo ha evolucionado la participación del salario en la distribución del ingreso durante los años $90 \mathrm{~s}^{4}$.

4 Este cociente suele utilizarse como Proxy de la distribución funcional del ingreso y ellos se deriva de la propia fórmula que establece que: (1) $\mathrm{W} /(\mathrm{Y} / \mathrm{L})=(\mathrm{W} . \mathrm{L}) / \mathrm{Y}$, donde $\mathrm{W}=$ salario real, $\mathrm{L}=$ Ocupados, $\mathrm{Y}=$ nivel de producto. Para mayores precisiones ver Santarcángelo et. al. (2012). 
Gráfico 3 Evolución de los salarios, la productividad laboral y el cociente salarios sobre productividad. 1991-2001 $(1991=100)$

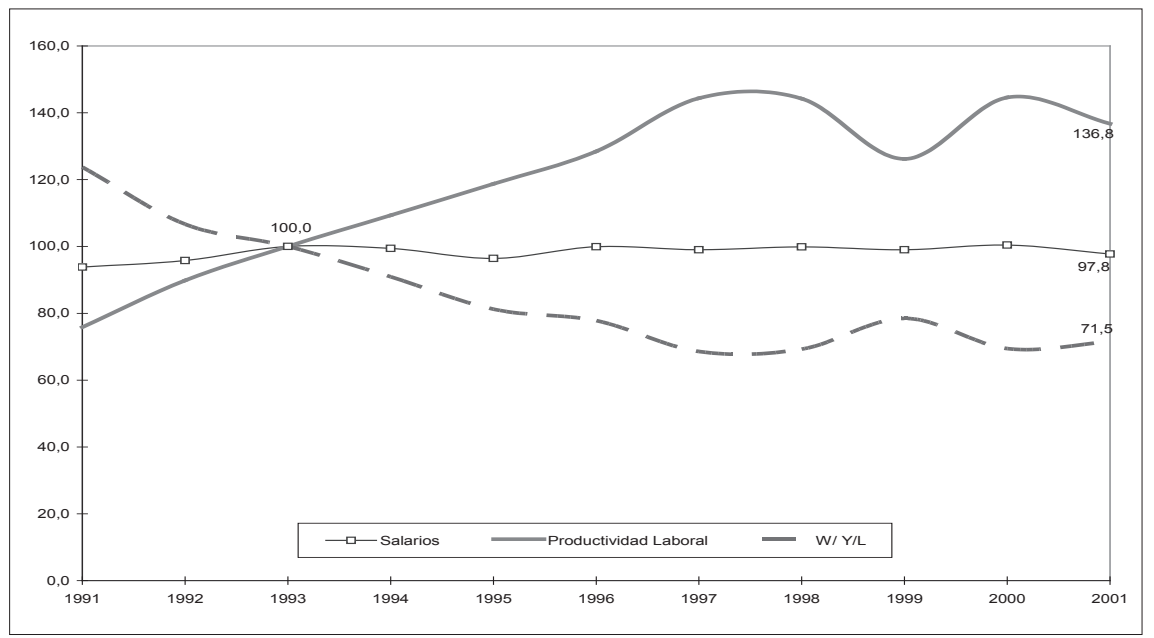

Fuente: Elaboración propia en base al INDEC, la EPH y el MTySS.

Como se puede apreciar en el gráfico, y en un contexto de incremento de la productividad laboral señalado al analizar el gráfico 2 , los salarios reales del sector han logrado mantenerse al nivel de comienzos de los años noventa registrando una leve caída del 3\% al estallar la crisis del 2001, en clara línea con lo sucedido con los salarios reales agregados para la economía que descienden para el mismo período un $1,5 \%$. Asimismo, si analizamos el cociente entre el nivel de salarios reales y la productividad laboral que sirve para dar cuenta de la evolución que ha mostrado la percepción de salarios en relación al producto generado, vemos que la participación del salario en el producto cae a lo largo de la década casi un $30 \%$ aunque sus niveles se estancan a partir de la recesión de finales de los años noventa. Como resulta evidente, los grandes perdedores de la transformación experimentada han sido los trabajadores que en el año 2001 reciben casi el $60 \%$ de lo que percibían en 1991. 


\section{LA SIDERURGIA DURANTE LA POSTCONVERTIBILIDAD}

La crisis social, política y económica de diciembre de 2001 significa tanto el final del gobierno de la Alianza como del régimen de convertibilidad. Se produce a la par la crisis del sistema financiero con circulación de cuasi-monedas, tasas de interés elevadas y la aplicación del "corralito" bancario. Hacia el año 2002, con Eduardo Duhalde electo como presidente provisional, se decreta del default de la deuda pública y la devaluación del peso de un orden del 30\% respecto al dólar y el consiguiente aumento de precios (Basualdo, 2006).

La devaluación del peso frente al dólar configura un nuevo escenario económico que permite el crecimiento de los sectores productores de bienes transables, por sobre la rama de los servicios. Sin embargo, la expansión de la industria en su conjunto ha estado vinculada no sólo a la alteración del tipo de cambio y de los precios relativos, sino a otros factores de competitividad no precio, dados por los incrementos en las innovaciones derivados de mayores gastos de inversión, y de la productividad del empleo que si bien se incrementó durante la convertibilidad, en los años siguientes su aumento será mucho más pronunciado (Santarcángelo et. al., 2011).

II.1 Vinculación del sector siderúrgico con el sector externo en la postconvertibilidad

$\mathrm{Al}$ igual que ocurriera cuando se presentaron los datos referidos a la vigencia del régimen convertible, la postconvertibilidad también presenta dos etapas claras con punto de inflexión en el año 2007, momento en el cual el sector manufacturero dejó de liderar la recuperación económica y comenzó a crecer a tasas anuales menores y comenzó paulatinamente a perder cierto protagonismo relativo (Santarcángelo et. al. 2012). De esta manera, la primera fase corresponde al período 2002-2007 en tanto que la segunda abarca el período 2008-2012.

En el gráfico 4 se exhibe la evolución de la producción siderúrgica por principal componente para el período 2002-2012. 
Gráfico 4 - Producción siderúrgica por principal componente, 2002-2012.

En miles de toneladas

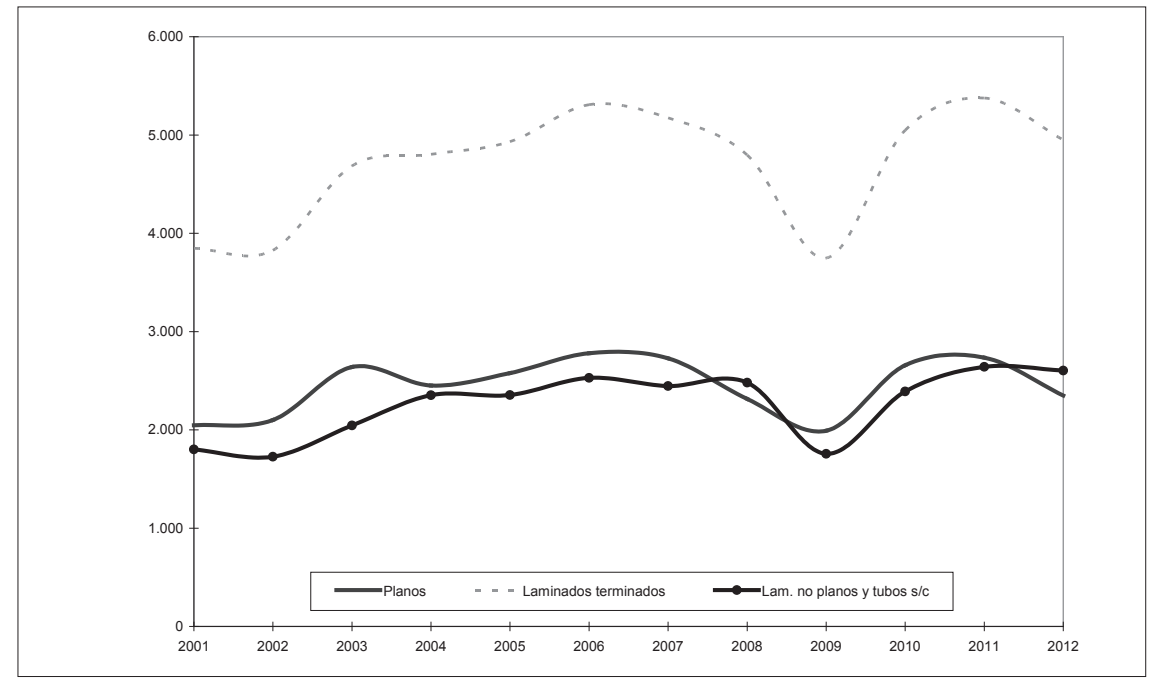

Fuente: Elaboración propia a partir de Azpiazu et. al. (2007) y Alacero (2012)

Como se observa en el gráfico, desde la crisis de 2001 hasta el año 2012, la producción siderúrgica se ha incrementado un $25 \%$ y ronda los 5.000 millones de toneladas, los cuales se componen casi por partes iguales de productos laminados planos y de laminados no planos y tubos sin costura. Las dos últimas categorías, que en el gráfico se presentan agrupadas, solo en el 2008 y 2012 tuvieron mayor peso en la producción total del sector que los laminados planos. Asimismo, se visualiza en el gráfico que a partir del 2007 se inaugura una fase decreciente para la industria siderúrgica (tanto para las categorías de laminados planos como de laminados no planos y tubos sin costura), de la misma forma que las rentabilidades de la cúpula decrecen a partir del impacto negativo de la crisis internacional (Basualdo et. al., 2012). De manera concomitante, a partir de ese mismo año se verifica un sensible incremento de los precios locales que se acelera con el devenir de los meses, reflejando un claro intento de los sectores más concentrados de la economía de evitar que los aumentos de salario real mermen los niveles de rentabilidad, teniendo en cuenta que hacia el año 2007 los salarios alcanzan el nivel del año 2001 (Santarcángelo y Perrone, 2011).

A pesar que desde mediados del año 2007 se observa una pérdida de dinamismo en lo que refiere a la producción sectorial, la recuperación posterior per- 
mite retornar a los niveles previos a la crisis. Sumado a ello, el crecimiento de la producción en la industria siderúrgica durante todo el periodo de la postconvertibilidad muestra un claro contraste con la década de los 90, en la cual el crecimiento sectorial si bien se mostró dinámico, fue sensiblemente menor, tanto en lo que refiere a la producción de hierro primario, de acero crudo como de laminados terminados en caliente (Gráfico 5). En lo que refiere a la producción de laminados planos en frío, la producción no ha variado mayormente entre los años 1993-2012.

Gráfico 5 - Evolución de la producción de hierro primario, acero crudo y planos laminados terminados en caliente y frío. 1993-2012.

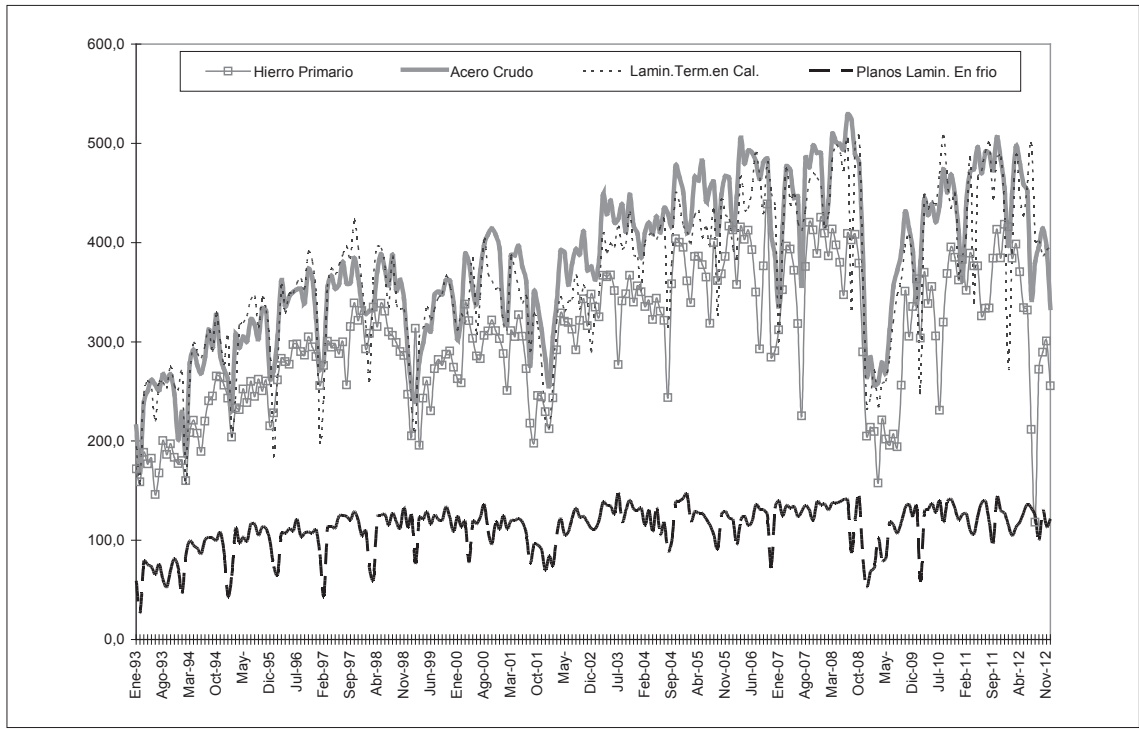

Fuente: Elaboración propia en base a Alacero (2012).

Asimismo, durante la postconvertibilidad no sólo se ha incrementado el nivel de producción sectorial, sino que, al igual que lo manifestado durante la década de los noventa, la dinámica productiva estuvo estrechamente vinculada a su orientación a los mercados externos (Schvarzer et. al., 2005). Esta relación se presenta en el gráfico 6 donde se analiza el peso de las exportaciones en relación al valor bruto de producción y la relación entre las importaciones y el consumo aparente. 
Gráfico 6 - Peso de las exportaciones en relación al valor bruto de producción y relación entre importaciones y consumo aparente, 1993-2012. En porcentaje.

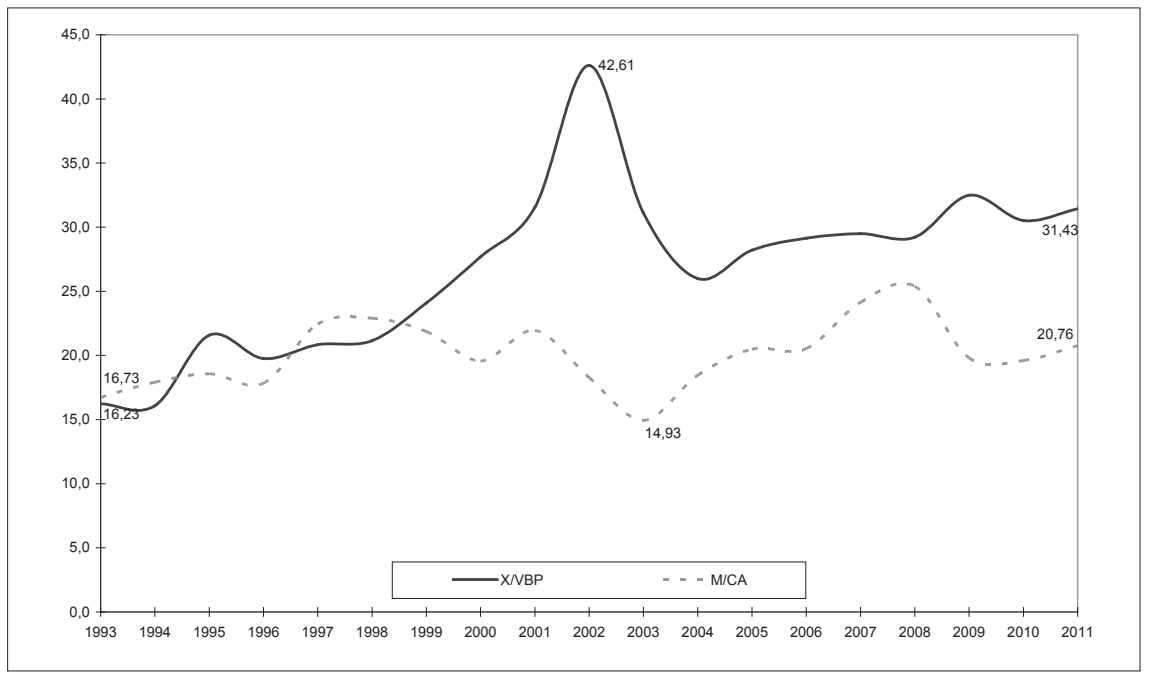

Fuente: Elaboración propia a partir de Azpiazu et. al. (2007) y Alacero (2012)

Como es posible apreciar, el nivel de exportaciones incrementa su peso relativo respecto al valor bruto de producción del conjunto de la industria siderúrgica, fenómeno que alcanza su valor máximo en el pico de la crisis en el año 2002. El abandono del régimen convertible implicó una significativa alteración de los precios relativos de la economía, que impactaron en un incremento de la competitividad sectorial para aquellas categorías de la siderurgia con fuerte inclinación exportadora (Schvarzer et. al., 2005). Luego de la crisis y a partir del año 2003, el peso de las exportaciones en el valor bruto de producción muestra una leve tendencia creciente a lo largo del período y termina con valores ligeramente superiores a los registrados en el año 2001.

Por otro lado, la relación entre importaciones y consumo aparente, que como se vio anteriormente refleja el peso de las importaciones sobre el consumo interno de dichos productos, varía a lo largo del periodo de acuerdo al dinamismo del mercado local. A partir de la depresión económica de 2001-2002 cae la relación M/CA (importaciones sobre consumo aparente), incluso a niveles más bajos que durante la convertibilidad producto de la fuerte contracción de la actividad económica. No obstante, desde el año 2003, en virtud del crecimiento económico y de una balanza comercial superavitaria, se inicia una recuperación de las importaciones sobre el 
consumo local que se extenderá hasta el año 2009, cuando se visualiza una nueva caída del cociente estudiado producto de la crisis internacional que luego se recupera y exhibe una crecimiento del orden del 40\% desde el valor registrado en 2003.

Esta dinámica productiva se dio a partir de un significativo aumento en la productividad laboral que crece más de un $80 \%$ desde el 2001. Para dar cuenta de este fenómeno, en el gráfico 7 se presenta la evolución del nivel de producción, la productividad laboral y la cantidad de obreros ocupados por la rama para el período bajo análisis.

Gráfico 7. Evolución de la producción en la industria siderúrgica, y de la productividad por hora y obrero ocupado, 2001-2011 $(1993=100)$

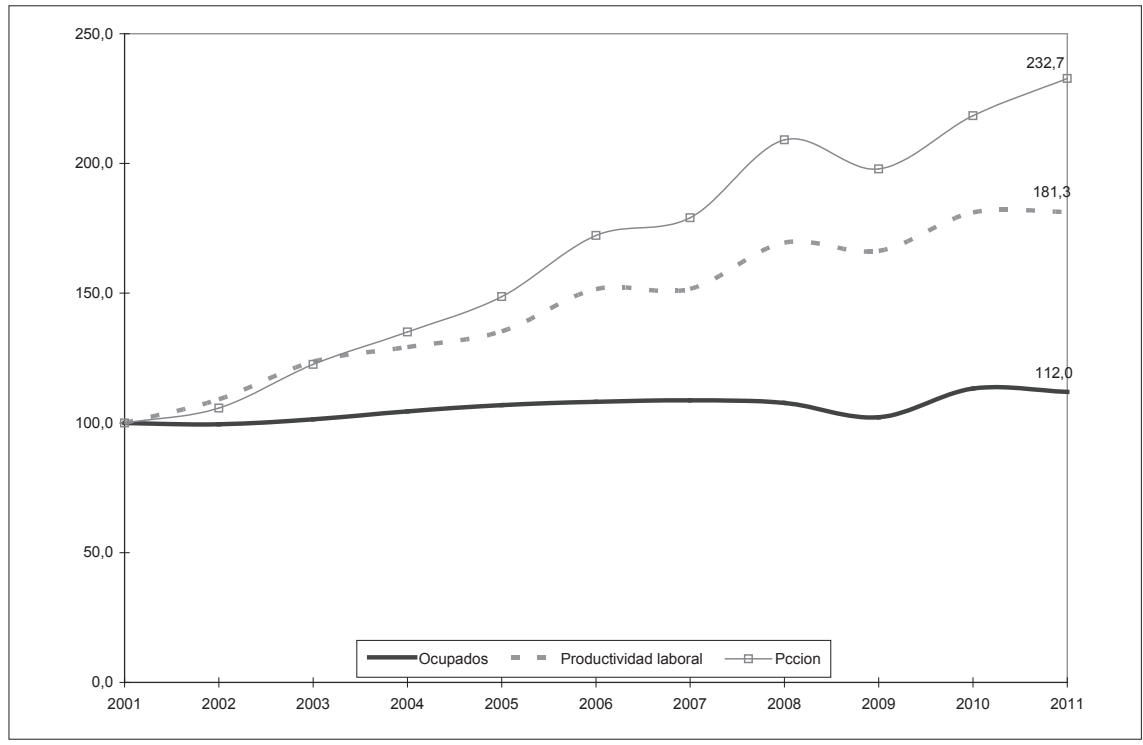

Fuente: Elaboración propia a partir de Azpiazu et. al. (2007) y Alacero (2012)

Como se refleja en el gráfico, entre los años 2001 y 2011 se produce un fuerte incremento de la producción sectorial, mientras que el nivel de empleo crece levemente, incluso reflejando una caída hacia el bienio 2008-2009 producto de la crisis internacional. La conjugación de ambos procesos explica el gran aumento de la productividad laboral de la industria siderúrgica durante la postconvertibilidad. 
No obstante, en lo que refiere a la evolución de la ocupación sectorial, debe destacarse una recuperación de la cantidad de puestos de trabajo durante esta etapa. La industria siderúrgica empleaba cerca de 47 mil trabajadores hacia 1975, aunque dicha cantidad de ocupados, producto de las privatizaciones y reestructuraciones neoliberales, se reduce a $32 \mathrm{mil}$ en 1989, para pasar a rondar los $13 \mathrm{mil}$ trabajadores hacia el fin de la convertibilidad en el año 2001. En el 2011, producto de la recuperación de la economía en general y del gran desempeño del sector en particular, la cantidad de ocupados asciende a 17700 aproximadamente (Aspiazu et al., 2007; Alacero, 2012).

\section{2 Productividad laboral e inversiones}

El aumento de la productividad y de los niveles de producción en el sector también se vincula con otra variable de relevancia durante la postconvertibilidad, que tiene que ver con el comportamiento de la inversión. Como se aprecia en el Cuadro 2, la evolución de las inversiones en la rama siderúrgica entre 2004 y 2011 ha significado un crecimiento del orden del 70\% para Argentina. El año 2008, previo al impacto de la crisis, mostró el mejor nivel de inversión sectorial equivalente a 425.119 miles de dólares.

Cuadro 2 - Inversiones en la rama siderúrgica en Argentina y América Latina en miles de dólares, 2004-2011.

\begin{tabular}{ccccccccc}
\hline & 2004 & 2005 & 2006 & 2007 & 2008 & 2009 & 2010 & 2011 \\
\hline Argentina & 160.512 & 195.118 & 320.676 & 312.443 & 425.119 & 203.090 & 235.113 & 272.923 \\
América \\
Latina \\
$\begin{array}{c}\text { \% Arg / A } \\
\text { Lat }\end{array}$ & 1.529 .435 & 3.425 .603 & 4.196 .690 & 3.849 .869 & 5.812 .835 & 6.056 .355 & 5.553 .622 & 4.988 .662 \\
\hline
\end{tabular}

Fuente: Elaboración propia en base a Alacero (2012)

No obstante, y en función de los datos aportados para América Latina, el peso de la inversión siderúrgica en Argentina respecto a la inversión sectorial en el continente ha disminuido, pasando a ser del 10,5\% en 2004 a 5,5\% en 2011. Esto se explica fundamentalmente por el crecimiento de la rama siderúrgica, y de la inversión en particular, en países como Brasil y México, que han incrementado su peso en Améri- 
ca Latina; y que para el mismo período han registrado tasas de crecimiento del $226 \%$ y del $498 \%$, cuando en nuestro país el crecimiento ha sido del orden del $70 \%$. Esto muestra que a pesar de ser un sector sumamente privilegiado en términos de rentabilidad local (como veremos en el siguiente cuadro), la inversión acumulada ha crecido a un ritmo que es un tercio del registrado en Brasil y un 70\% menor al de México ${ }^{5}$.

\section{3 Rentabilidad del sector}

Otra variable de extrema relevancia para medir el desempeño sectorial en esta etapa tiene que ver con la rentabilidad de la industria siderúrgica, particularmente en lo que refiere a las empresas de la cúpula. A continuación, en el Cuadro 3, se presentan datos correspondientes a la rentabilidad de la cúpula empresaria argentina (compuesta por el conjunto de 500 empresas de mayor volumen de ventas del país) y de la cúpula siderúrgica para la postconvertibilidad (compuesta por el conjunto de empresas que operan en el sector siderúrgico y pertenecen al conjunto de 100 empresas con mayor volumen de ventas que operan en el sector manufacturero) $)^{6}$.

En lo que refiere a la rentabilidad sectorial durante la postconvertibilidad, esta se ha incrementado sensiblemente respecto a la década de los noventa. El mayor salto de incremento de rentabilidad se efectúa en el periodo 2002-2007, donde prácticamente se quintuplican los niveles de rentabilidad respecto al último subperíodo de la convertibilidad (1998-2001). Sin dudas, esta impresionante variación tiene que ver con la alteración del tipo de cambio que supuso la reducción de los costos salariales y la inserción de un fuerte shock de competitividad para todas aquellas ramas eminentemente exportadoras, como lo ha sido el caso de la siderurgia, que sostuvieron sus costos en pesos a la par que vendieron sus producciones en dólares (Basualdo et. al, 2012; Santarcángelo et. al., 2012; Schorr et. al., 2005).

5 Las inclinaciones inversoras presentan una fuerte relación con el costo laboral en otros países. A tal efecto es ilustrativo el comentario realizado por Paolo Rocca (Grupo Techint) en septiembre de 2012, cuando sostuvo que: "El costo de un obrero industrial en la Argentina es de 24 dólares por hora, contra 12 dólares en México y 9 dólares en Brasil. Eso sí, el operario argentino sigue siendo el más calificado", Diario Clarín, 05/09/2012. Disponible online: http://www.ieco.clarin.com/economia/Criticas-Paolo-Rocca-politicaindustrial_0_768523217.html

6 Por cúpula empresaria se entiende al conjunto de 500 empresas de mayor nivel de facturación; por cúpula industrial se entiende al conjunto de 100 empresas de mayor volumen de ventas del país que operan en dicho sector; y por cúpula siderúrgica está compuesta por el conjunto de empresas que operan en el sector y se encuentran dentro de la cúpula industrial. 
Cuadro 3 - Rentabilidad de la cúpula empresaria y de la cúpula siderúrgica en Argentina. Promedio anual, 1991-2011.

\begin{tabular}{lllllll}
\hline & $\begin{array}{l}1991- \\
1993\end{array}$ & $\begin{array}{l}1994- \\
1997\end{array}$ & $\begin{array}{l}1998- \\
2001\end{array}$ & $\begin{array}{l}2002- \\
2004\end{array}$ & $\begin{array}{l}2002- \\
2007\end{array}$ & $\begin{array}{l}2008- \\
2011\end{array}$ \\
\hline $\begin{array}{l}\text { Promedio empresas } \\
\text { siderúrgicas }\end{array}$ & $-6,3$ & 1,5 & 3,3 & 23,1 & 16 & 14 \\
$\begin{array}{l}\text { Promedio cúpula } \\
\text { empresaria 500 }\end{array}$ & 1,6 & 5,1 & 2,2 & 8,5 & 12 & 12 \\
\hline
\end{tabular}

Fuente: Elaboración propia en base a la ENGE (Encuesta Nacional de Grandes Empresas, INDEC) y la base de economía política de la UNGS.

A partir de la crisis internacional, los niveles de rentabilidad (en promedio) muestran un leve descenso cercano al 3\%, por lo que aún así se mantienen muy por encima del promedio de rentabilidad de la cúpula siderúrgica en los tres subperíodos de la convertibilidad. Por otro lado, y en relación con el comportamiento del promedio de rentabilidad de la cúpula empresarial en su conjunto, la rentabilidad de la cúpula siderúrgica en la convertibilidad se mantuvo por debajo del promedio de la cúpula empresarial para los subperíodos 1990-1993 y 1994-1997, producto del proceso de transformaciones sectoriales. Sin embargo, en un contexto de recesión económica signado por el subperíodo 1998-2001 la rentabilidad siderúrgica superó en un $30 \%$ aproximadamente la rentabilidad del conjunto de la cúpula empresarial.

Finalmente, durante la postconvertibilidad, la rentabilidad de la cúpula siderúrgica fue superior en ambos subperíodos a la rentabilidad de la cúpula empresarial, reflejando, de esta manera, que la rama siderúrgica ha sido una de las ramas "ganadoras" durante la presente etapa, a partir de la mejora de la competitividad producto de diversos factores ya mencionados (régimen cambiario, orientación exportadora, reducción costos salariales, incremento de la inversión sectorial). Es interesante remarcar que si bien el promedio de rentabilidad es del 14\%, durante los primeros años de la postconvertibilidad la rentabilidad llegó a ser de casi el $24 \%$ (por ejemplo en el 2004) para luego reducir su peso llegando en el año 2011 a ser del $12 \%$.

\section{4 Comportamiento salarial}

Respecto al comportamiento del salario real, en el Gráfico 8 se presenta la evolución de los salarios reales en el sector, la productividad laboral y el cociente salarios sobre productividad. 
Gráfico 8. Evolución de la productividad por obrero ocupado, el salario real y el cociente entre salario real y productividad laboral en la industria siderúrgica, $1991-2011(2001=100)$

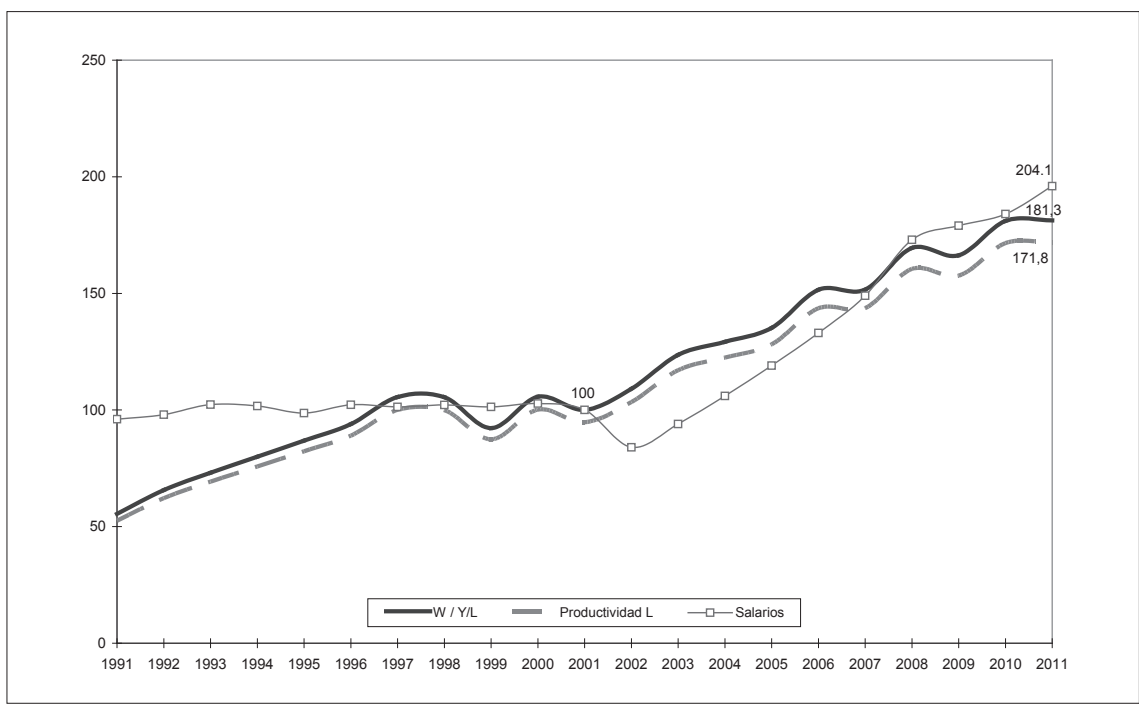

Fuente: Elaboración propia en base a EPH y datos del MTEySS

Como es posible apreciar a partir del gráfico, luego del estancamiento salarial a lo largo de la década de los noventa y de la pronunciada caída del salario real con la devaluación del año 2002, se inicia un persistente proceso de recuperación de los niveles salariales que se extiende durante la postconvertibilidad (20012011). El crecimiento salarial se estanca con la crisis internacional que tuvo su impacto hacia los años 2008 y 2009. No obstante, la implementación del Programa de Recuperación Productiva ${ }^{7}$ (REPRO) por parte del gobierno nacional benefició en gran medida a las empresas siderúrgicas y permitió, de algún modo, evitar una caída mayor de los niveles salariales. Finalmente, hacia el año 2010 se observa una nueva recuperación de los salarios luego de la crisis.

En relación a la productividad laboral (por obrero ocupado), durante los años 90 la misma presenta un nivel inferior a la evolución de los salarios reales. No obstante, la brecha existente entre productividad y salarios se reduce de mane-

7 Es una herramienta de contingencia presente en la normativa del MTEySS de Nación, que se aplicó durante la crisis y consistió en un subsidio que apuntó a solventar una parte del salario (600 pesos) de los trabajadores. Para más información: www.trabajo.gov.ar 
ra creciente a lo largo de la década, producto de la desregulación y flexibilización laboral de las políticas neoliberales así como también de las propias modificaciones sectoriales vinculadas a la introducción de nuevos métodos de organización del trabajo y de polivalencia funcional en la siderurgia (Jabbaz, 1996). Particularmente en los periodos de crisis 1997-1998 y 2000-2001 la productividad laboral alcanza el nivel de los salarios reales en el sector.

Con el fin del régimen de convertibilidad, la productividad laboral pega un salto brusco elevándose significativamente por encima de los niveles salariales. Este proceso ocurre particularmente entre los años 2002 y 2007. En el mismo periodo, sin embargo, se observa una creciente incidencia relativa de los salarios producto de la recomposición de las negociaciones colectivas durante la etapa. En esta dirección, hacia el año 2007 los salarios reales superan el nivel de la productividad sectorial y logran sostener el nivel alcanzado por encima de la productividad durante los años subsiguientes.

Finalmente, la relación entre salarios reales y productividad laboral (que da cuenta de la evolución de la distribución funcional del ingreso para el sector) muestra una tendencia ascendente a lo largo de la década 2001-2011 lo que implica una mayor incidencia de los salarios respecto a la producción siderúrgica, con algunos altibajos relativos de los impactos de la crisis internacional.

\section{CONCLUSIONES}

El proceso de desindustrialización iniciado por la dictadura militar a mediados de los años setenta fue significativamente profundizado durante los años noventa por el gobierno de Menem. Haciéndose eco de las políticas sustentadas en el Consenso de Washington y fuertemente promocionadas por los organismos multilaterales de crédito como el Fondo Monetario Internacional y el Banco Mundial, y teniendo como eje la paridad cambiaria entre el peso argentino y el dólar, se aplicaron un vasto conjunto de políticas que lograron consolidar la supremacía de las leyes de mercado y la desregulación de la economía; y que lograron apuntalar al sector financiero como eje central del modelo de acumulación local.

Durante los años de vigencia del régimen convertible, si bien el sector siderúrgico exhibe tendencias generales registradas por la industria manufacturera argentina en su conjunto, como la reducción de la demanda interna de bienes industriales, la drástica caída en los niveles de empleo (superiores al 23\%) y la caída de los salarios; el complejo siderúrgico logra incrementar su volumen de 
producción a partir de aprovechar las políticas de promoción existentes y mediante la obtención de beneficios por las grandes empresas con estrechas relaciones con el poder político; pero fundamentalmente, porque traslada su demanda al sector externo. En plena crisis de finales de los años noventa y como vimos a lo largo del trabajo, en un contexto donde el consumo y la demanda interna se reducen, las principales empresas que operan en el sector comienzan a ubicar crecientemente sus volúmenes de producción en mercados externos. En este sentido, la creciente orientación exportadora que registra el sector, fundamentalmente de laminados planos terminados (que duplica en cuatro años sus montos exportados) permitieron aumentar los volúmenes de producción. Asimismo, el nivel de rentabilidad de las empresas que operan en el sector se transforma a lo largo de la década pasando de ser negativa a comienzos del régimen convertible para volverse positiva en los años pico de la crisis.

Con el fin del régimen de convertibilidad, la devaluación de la moneda, la consecuente reducción en los niveles salariales y la aún mayor reducción del costo salarial del sector, provocaron en primera instancia un significativo incremento en los niveles de rentabilidad. Como resultado, los niveles de rentabilidad se incrementan significativamente llegando, en promedio, a ser del 16\% para las empresas de la cúpula siderúrgica, que de este modo obtuvieron rendimientos que en promedio fueron más de un $30 \%$ superiores a los registrados por la elite empresaria local. Durante estos años, se destaca el desempeño productivo de las empresas Tenaris/ Siderca y Ternium/Siderar que lideran los niveles de rentabilidad del sector y que en conjunto facturaron alrededor del $90 \%$ de la elite siderúrgica. Por otra parte, durante los últimos años analizados y como producto del proceso de recuperación salarial registrado por la economía argentina, la rentabilidad del sector se ha visto reducida levemente (en 2 puntos porcentuales) aunque sigue ubicándose en niveles superiores a los registrados por la elite empresaria argentina.

Una de las explicaciones de esta dinámica viene dada por el sostenido incremento en la productividad laboral que ha mostrado un crecimiento constante en ambos períodos bajo análisis. Como pudimos ver, durante la convertibilidad, el claro proceso de expulsión de mano de obra junto con los procesos de flexibilización, precarización laboral, congelamientos salariales y la introducción de nuevos métodos de producción vinculados al toyotismo (Jabbaz, 1994), implicaron una reducción significativa en el empleo sectorial así como una disminución de los salarios reales y del costo salarial. Luego del abandono de la paridad cambiaria, la productividad laboral alcanza aún mayores incrementos (superiores al 70\%) en un contexto en el que los aumentos en los volúmenes de producción superan holgadamente el aumento registrado en el nivel de empleo sectorial (que como vimos 
crece un 11\% para el período 2001-2011). Si bien esta recuperación de la ocupación sectorial marca una ruptura con el proceso constante de expulsión de mano de obra atravesado por el sector desde 1975, la creación cercana de 1000 puestos de trabajos ubica el nivel de empleo sectorial en niveles ligeramente inferiores a los que la economía poseía a un año de la crisis del 2001.

En este contexto de significativo incremento de la productividad y rentabilidad, las empresas que operan en el sector profundizaron su orientación exportadora llegando el peso de las exportaciones sobre el volumen bruto de producción a ser cercano al 32\% en el año 2011. Esto da cuenta de que a pesar del crecimiento que experimenta el sector industrial en este período y del incremento de la demanda local de bienes siderúrgicos, la rama siderúrgica ha incrementado su dependencia de la demanda externa en un contexto en el que la producción y las exportaciones han crecido un $232 \%$ y un $290 \%$ respectivamente para el período 2001-2011. Del mismo modo, si bien el peso de las importaciones sobre el consumo aparente se reduce durante los dos primeros años de la postconvertibilidad como consecuencia del encarecimiento de los bienes importados, a partir del año 2004 la tendencia se revierte y termina con un crecimiento cercano al 40\%. Esto refleja que el sector siderúrgico durante la postconvertibilidad ha profundizado su dependencia del sector externo no sólo como mercado donde ubicar sus productos sino como insumo indispensable para llevar adelante su producción.

De manera concomitante, otro importante rasgo de continuidad que se registra entre los períodos analizados es el aumento del proceso de concentración sectorial. Esto se debe al proceso de reestructuración que supuso la crisis del año 2001 y en función de la existencia de fusiones y adquisiciones, así como del avance de la extranjerización. En este sentido, ha sido muy importante la compra en el año 2007 de Acindar por parte de Arcelor Mittal, empresa de capital hindú y que es la primera firma productora de acero a nivel mundial; así como el proceso de expansión del Grupo Techint en el resto de América Latina que ha logrado ubicarse en el puesto número 8 entre las empresas siderúrgicas a nivel mundial. Entre las principales firmas que este grupo ha adquirido en los últimos años, puede citarse la compra de Imsa, la mexicana Tamsa, la empresa colombiana Ferrasa y la participación en el gigante siderúrgico brasileño Usiminas, entre otras.

Como hemos podido apreciar, el sector siderúrgico ha logrado un desempeño productivo que lo ubica como uno de los grandes ganadores industriales de la postconvertibilidad. Esto se debe a que el sector ha logrado incrementar significativamente su capacidad productiva a la vez que ha logrado revertir la tendencia decreciente de la participación del salario en el producto. El lado negativo de esta 
evolución es el escaso peso que tiene el empleo sectorial en el total ya que a pesar de lograr aumentos en el volumen de producción cercanos al 300\%, el empleo sectorial es similar al que la economía tenía en el año 2001. Pero el principal desafío que actualmente enfrenta el sector es su creciente dependencia del sector externo que hoy no sólo es central como demanda de productos sino como proveedor de insumos clave para llevar adelante la producción. Esto evidencia que la desarticulación del entramado productivo sectorial sufrido desde mediados de los años setenta, lejos de haberse revertido, se ha profundizado en los últimos años. Desandar el legado de desindustrialización más severo de nuestra historia requiere de políticas estatales específicamente diseñadas para lograr cambios en la estructura productiva. Se necesita mucho más que la instauración de un tipo de cambio competitivo. Es hora de transformar de raíz nuestra matriz productiva.

\section{BIBLIOGRAFÍA}

Azpiazu, D., Basualdo, E. \& Kulfas, M. (2007). La industria siderúrgica en Argentina y Brasil durante las últimas décadas. Buenos Aires: CEFS - FETIA - CTA.

Basualdo, E. (2006). Estudios de Historia Económica Argentina. Buenos Aires: FCE.

Basualdo, E. (2011). Sistema Político y Modelo de Acumulación. Tres ensayos sobre la Argentina actual. Buenos Aires: Cara o Ceca.

Basualdo, E., Manzanelli, P. \& Schorr, M. (2012). Elite empresaria y régimen económico en Argentina. Las grandes firmas en la post-convertibilidad. Buenos Aires: FLACSO.

Cohn, E. (2009). El rol de la industria siderúrgica en Argentina: tensiones y transformaciones del sector desde sus inicios hasta la actualidad. Buenos Aires: UBA.

Jabbaz, M. (1996). Modernización social o flexibilidad salarial. Buenos Aires: CEAL.

Jerez, P. (2008). La exportación como destino alternativo para la producción siderúrgica argentina entre 1976 y 1990, Revista H Industria, 2(3), 1-20.

Moya, D. (2012). Prospectiva tecnológica. Complejo Siderurgia y no ferrosos, Mímeo.

Santarcángelo, J. \& Perrone, G. (2011). La lógica de la cúpula empresaria en la disputa por el excedente, Realidad Económica (259).

Santarcángelo, J. \& Perrone, G. (2012). La industria siderúrgica argentina en la post-Convertibilidad. Una mirada desde la cúpula empresaria, mimeo, UNGS. 
Schorr, M. \& Ortiz, R. (2007). La rearticulación del bloque de poder en Argentina en la post-convertibilidad", Revista Papeles de Trabajo año 1(2).

Schvarzer, J. \& Papa, J. (2005). La producción y la capacidad instalada en la industria siderúrgica y del aluminio: un balance de los cambios empresarios, tecnológicos y de mercado durante las últimas dos décadas, Documento de Trabajo $\mathrm{N}^{\circ} 7$, Buenos Aires: CESPA,

von Storch, M. V. (2005). Análisis comparado de los impactos de las privatizaciones de Altos Hornos Zapla en Palpalá, SOMISA en San Nicolás e YPF en Comodoro Rivadavia, a la luz de los cambios post convertibilidad. $7^{\circ}$ Congreso Nacional de Estudios del Trabajo. 